\title{
Abnormalities in Zinc Homeostasis in Young Infants with Cystic Fibrosis
}

\author{
NANCY F. KREBS, JAMIE E. WESTCOTT, THOMAS D. ARNOLD, BENZI M. KLUGER, \\ FRANK J. ACCURSO, LELAND V. MILLER, AND K. MICHAEL HAMBIDGE
}

Department of Pediatrics, University of Colorado School of Medicine, Denver, Colorado 80262, U.S.A.

\begin{abstract}
ABSTR
Low plasma zinc concentrations have been reported in ap-
proximately $30 \%$ of young infants with cystic fibrosis identified
by newborn screening. The objective of this study was to exam-
ine zinc homeostasis in this population by application of stable
isotope methodology. Fifteen infants with cystic fibrosis $(9$ male,
6 female; 7 breast-fed, 8 formula-fed) were studied at a mean
( \pm SD) age of $1.8 \pm 0.7$ mo. On $\mathrm{d} 1,{ }^{70} \mathrm{Zn}$ was administered
intravenously, and ${ }^{67} \mathrm{Zn}$ was quantitatively administered with all
human milk/formula feeds during the day. Three days later, a 3-d
metabolic period was initiated, during which time intake was
measured and complete urine and fecal collections were ob-
tained. Fractional zinc absorption, total absorbed zinc, endoge-
nous fecal zinc, and net absorbed zinc were measured; fecal fat
excretion was also determined. Fractional absorption was signif-
icantly higher for the breast-fed infants $(0.40 \pm 0.21)$ compared
with the formula-fed group (0.13 \pm 0.06$)(p=0.01)$, but with the significantly higher dietary zinc intake of the formula-fed
\end{abstract}

group, total absorbed zinc was higher for those receiving formula $(p=0.01)$. In 11 infants with complete zinc metabolic data, excretion of endogenous zinc was twofold greater for the formula-fed infants $(p<0.05)$; net absorption ( $\mathrm{mg}$ zinc/d) was negative for both feeding groups: $-0.04 \pm 0.52$ for breast-fed; $-0.28 \pm 0.57$ for formula-fed. Endogenous fecal zinc losses correlated with fecal fat excretion $(r=0.89, n=9, p=0.001)$, suggesting interference with normal conservation of endogenously secreted zinc. These findings indicate impaired zinc homeostasis in this population and suggest an explanation for the observations of suboptimal zinc status in many young infants with cystic fibrosis prior to diagnosis and treatment. (Pediatr Res 48: 256-261, 2000)

\section{Abbreviation \\ AAS, atomic absorption spectrophotometer}

The prevalence of zinc deficiency in individuals with cystic fibrosis has been an area of some uncertainty. Young infants, because of their rapid rates of growth, have relatively high physiologic zinc requirements. There have been several reports of young infants with cystic fibrosis presenting with signs and symptoms of severe zinc deficiency (1-3). Previous observations from the Colorado Newborn Screening Program suggested that zinc status was frequently suboptimal by $6 \mathrm{wk}$ of age in infants found to have cystic fibrosis. Nearly $30 \%$ of subjects were found to have plasma zinc concentrations below the normal range, consistent with moderate zinc deficiency. In the same infants, treatment with pancreatic enzymes was associated with significant increases in plasma zinc concentrations (4). To investigate the potential underlying perturbations, we undertook detailed studies of zinc metabolism in these infants by the application of zinc stable isotope methodology.

Received December 9, 1998.; accepted September 15, 1999.

Correspondence: Nancy F. Krebs, M.D., Department of Pediatrics, University of Colorado School of Medicine, 4200 East Ninth Ave., Box C225, Denver, CO 80262, U.S.A.

This work was supported by NIH grants RR00069, T32-DK07658, DK02240, DK48520, \#2T73MC00011-04, andCA49981; and by the Pew Nutrition Fellowship T86-00279-023.
The objectives were to examine fractional absorption and fecal excretion of endogenous zinc according to type of feeding and degree of fat malabsorption.

\section{METHODS}

Study design. This was a cross-sectional study of zinc homeostasis in young infants with cystic fibrosis who were identified by newborn screening. Oral and intravenous administration of zinc stable isotopes was combined with traditional metabolic collections to measure dietary zinc intake, fractional absorption of exogenous dietary zinc, and fecal excretion of endogenous zinc; net zinc absorption was calculated. Fecal fat excretion, absolute and as a percentage of intake, was also measured. Stable zinc isotopes were administered intravenously and orally on $\mathrm{d} 1 ; 3 \mathrm{~d}$ later a metabolic period was initiated, which included measurement of milk intake for $3 \mathrm{~d}$, and complete urine and fecal collections for a total of $5 \mathrm{~d}$.

Subjects. Fifteen infants (nine male, six female) diagnosed between 1991 and 1994 through the Colorado Newborn Screening Program were studied (5). The zinc studies reported herein were completed during a comprehensive hospitalization in the Pediatric Clinical Research Center, which was under- 
taken after confirmation of the diagnosis, and which involved 72-h fecal fat collection, blood tests for clinical and other research protocols, pulmonary function testing, and family education about cystic fibrosis. Since these studies were completed, genotyping has become routinely available and is completed on all patients identified through the newborn screening program. Of the 15 subjects in this study, 10 were homozygous for $\Delta \mathrm{F} 508$, and 5 were $\Delta \mathrm{F} 508$ heterozygous. Infants with meconium ileus (with or without surgical resection), hypoalbuminemia, or on mixed feeding were excluded. After careful explanation of the purpose and the procedures of the study, consent was obtained from all subjects' parents. The study was approved by the Colorado Multiple Institutional Research Review Board.

Dietary intake. Infants were maintained on their preadmission diet for the entirety of the study. Intake was either exclusive human milk or infant formula; infants receiving mixed feedings of human milk and formula were excluded. None of the infants received solid foods before or during the course of the study. From d 4-7, intake of human milk was determined by test-weighing (pre- and postfeed infant weights) with a digital electronic balance accurate to $1 \mathrm{~g}$, which integrates 100 rapid serial measurements to provide a mean weight (Sartorius Corp., Bohemia, NY, U.S.A.) (6). For formula-fed infants, ready-to-feed products were used when available. For preparations available in powdered form only, formula was mixed in the hospital formula lab according to standardized procedures. Intake of formula was quantified by weighing bottles before and after all feeds on a balance accurate to $0.01 \mathrm{~g}$. For all infants, during the metabolic period (d 4-7), regurgitations were collected on wash cloths that were weighed before and after the feed; the weight of any collected milk/ formula was subtracted from the weight of the feed. A 5-mL sample of human milk was obtained for zinc analysis midway through each feed during the metabolic period. Previously obtained data have demonstrated that zinc concentrations in human milk are not significantly influenced by stage of feed (7). Aliquots of formula were also obtained from each bottle of formula for zinc analysis. Fat content of milk and formulas was taken from the literature (8) and from manufacturers' data, respectively.

Isotope preparation and administration. Zinc oxide powders enriched with ${ }^{70} \mathrm{Zn}(99.72 \%$ abundance $)$ and ${ }^{67} \mathrm{Zn}$ (89.62\% abundance) were obtained from Oak Ridge National Laboratories (Oak Ridge, TN, U.S.A.) and prepared using standard sterile techniques. Accurately weighed quantities of isotope were dissolved in $0.5 \mathrm{~N} \mathrm{H}_{2} \mathrm{SO}_{4}$, diluted in triply deionized water, titrated with metal-free ammonium hydroxide to a $\mathrm{pH}$ of 6 for the intravenous preparation and a $\mathrm{pH}$ of 5 for oral preparations. Prior to dosing each subject, zinc concentrations in isotope preparations were determined in triplicate by atomic absorption spectrophotometry, with correction made for the higher atomic weight of the enriched zinc. The ${ }^{70} \mathrm{Zn}$ preparation was tested for pyrogens (Limulus Amebocyte Lysate Kit, Whittaker Bioproducts, Walkersville, MD, U.S.A.) within $24 \mathrm{~h}$ prior to i.v. administration.

The infants' diets (formula or expressed human milk) were extrinsically labeled with accurately weighed doses of ${ }^{67} \mathrm{Zn}$ and allowed to equilibrate for at least $4 \mathrm{~h}$ before feeding. An accurately weighed amount (approximately $30 \mu \mathrm{g} / \mathrm{kg}$ of body weight) of ${ }^{70} \mathrm{Zn}$ was quantitatively infused over $5 \mathrm{~min}$ on $\mathrm{d} 1$. This was followed by repeated rinsing of the syringe to assure administration of complete dose. On the same day, between 100 and $725 \mu \mathrm{g}{ }^{67} \mathrm{Zn}$ was given with three to four feeds over an 8- to 12 -h period on $\mathrm{d} 1$. The oral isotope doses were calculated to equal approximately $10 \%$ of the infant's estimated daily zinc intake, and was thus much higher for the formula-fed infants. Bottles of labeled human milk or formula were weighed to the nearest $0.01 \mathrm{~g}$ before and after each feed to determine amount of label ingested. Ashless filter papers were used to collect any regurgitations. Total zinc and isotopic enrichment were subsequently determined on the regurgitations and subtracted from the administered dose.

Metabolic collections. Baseline stool and urine collections were obtained before isotope administration on $\mathrm{d} 1$. For the metabolic collections on d 4-8, an infant metabolic bed was set up in the hospital crib. The bed allowed the infant's naked bottom to rest over a plastic-lined pot below, into which stools were collected. Continuous urine collections were also obtained in 12-h pools on $\mathrm{d} 4-8$. A plastic recloseable bag was adhered to the infant's skin with tape over an adherent patch (Stomadhesive Wafer, Squibb, Inc., New Brunswick, NJ, U.S.A.). Urine was removed frequently from the distal end with a zinc-free syringe. Nursing staff were all trained in the stool and urine collection procedures and avoidance of zinc contamination was emphasized for all procedures. On d 4, a brilliant blue marker $(\sim 1 \mathrm{mg} / \mathrm{kg})$ was mixed with a small amount of milk or formula and given with the next feed. A second marker-labeled feed was given $72 \mathrm{~h}$ later to demarcate the metabolic period. A naked weight was obtained on the electronic balances each morning on $\mathrm{d} 4-8$.

Laboratory analyses. Milk, stool, and urine analyses for total zinc and isotopic enrichment were performed as previously described $(9,10)$. Fecal samples before and after the metabolic period were pooled into 12-h homogenates. Stools passed during the metabolic period were pooled according to passage of the brilliant blue marker. All stools in a pool were homogenized in a blender with small-sized, zinc-free, stainless steel jars and blades. A quantitative aliquot $(10-20 \mathrm{~g})$ from the 3-d pool was sent for fecal fat analysis (11); the remainder was used for measurement of total zinc and isotopic enrichment. Stools were ashed in the muffle furnace at $450^{\circ} \mathrm{C}$, wet digested with concentrated nitric acid, and ashed again at $450^{\circ} \mathrm{C}$. The ashed samples were quantitatively dissolved in $6 \mathrm{~N} \mathrm{HCl}$ and total zinc was determined with an atomic absorption spectrophotometer (AAS) fitted with a deuterium arc background correction lamp (Perkin-Elmer, Norwalk, CT, U.S.A.). Pancreatic enzymes capsules were also analyzed for zinc content, because zinc is a cofactor for the pancreatic carboxypeptidases. Triplicates of five capsules each (Pancrease MT 4, McNeil Pharmaceutical, Spring House, PA, U.S.A.) were ashed in the muffle furnace as described above for fecal samples. Total zinc was determined on AAS as described above, and was found to be $<5 \mu \mathrm{g}$ zinc per capsule.

Zinc was separated from other inorganic elements by ion exchange chromatography with AG 1 ion exchange resin (Bio- 
Rad Laboratories, Richmond, CA, U.S.A.). Percent isotopic enrichment was then determined by fast atom bombardmentinduced secondary ion mass spectrometry on a double-focusing mass spectrometer (model VG 7070E HF; Fisons-VG Analytical, Manchester, U.K.) equipped with an Ion Tech (London, U.K.) atom gun. The mass spectrometer was operated at low resolution, and ion counting detection and peak switching were used to measure ${ }^{70} \mathrm{Zn} /{ }^{66} \mathrm{Zn}$ and ${ }^{67} \mathrm{Zn} /{ }^{66} \mathrm{Zn}$ ratios; sample enrichments were derived using a standard curve (12).

Processing of urine samples included wet digestion, followed by ashing in muffle furnace. Reconstituted ash was applied to chelating resin and ion exchange columns to remove other mineral elements (13). Isotopic enrichment in the resulting solutions was measured as described above. Samples of enriched milk and regurgitated milk on filter papers were processed by similar methods as for fecal samples, and total zinc and isotopic enrichment were similarly determined. Zinc concentrations were obtained for human milk samples by analyzing a sample from each feed (9), or for formula by ashing samples and determining zinc concentration by AAS.

Calculations. Total dietary zinc $(\mathrm{mg} / \mathrm{d})$ was determined by multiplying zinc concentration of milk or formula by grams of milk per feed between markers.

Fractional absorption was determined from the ratio of the urine enrichments of the oral isotope to the intravenous isotope measured after $\mathrm{d} 3$, taking into account the size of the isotope doses (13). Total absorbed zinc (mg/d) was calculated by multiplication of dietary zinc and fractional absorption.

Excretion of endogenous fecal zinc $(\mathrm{mg} / \mathrm{d})$ was determined by an isotope dilution method according to the formula $\Sigma \mathrm{F}$. $\mathrm{f} /(\mathrm{u} \cdot \mathrm{d})$, where $\mathrm{F}$ equals the total $\mathrm{Zn}$ in fecal pool collected between the appearance of colored fecal markers; $f$ equals enrichment of intravenous isotope $\left({ }^{70} \mathrm{Zn}\right)$ in fecal pool; u equals average enrichment in urine of intravenous isotope during same time interval; and d equals time $(3 \mathrm{~d})$ during metabolic collections (14). Net absorption of zinc was calculated as the difference between total absorbed zinc and endogenous fecal zinc.

Data analysis. Data are presented as mean $\pm \mathrm{SD}$; the measured or calculated end points were compared according to feeding type by two sample $t$-tests. Spearman correlation was applied to correlation between fractional absorption and coefficient of fecal fat excretion and between endogenous fecal zinc and absolute fecal fat excretion. All statistical procedures were performed by the Statistix 3.5 program (Analytical Software, St. Paul, MN, U.S.A.). Statistical significance was considered at $p<0.05$.

\section{RESULTS}

The means of age, weight, plasma zinc concentration, and percent fecal fat excretion for the subjects were similar between the human milk and formula groups (Table 1). Ages of the infants at the time of the studies ranged from 1.0 to $3.6 \mathrm{mo}$. All but two of the infants were gaining weight during the metabolic studies, with the mean rate of $19 \pm 28 \mathrm{~g} / \mathrm{d}$ (range $40-77 \mathrm{~g} / \mathrm{d}$ ). Two infants with weight gain $>50 \mathrm{~g} / \mathrm{d}$ were both breast-fed, one who was pancreatic sufficient and one who had been started on enzymes before admission. Fecal fat excretion data were unavailable for four infants due to errors in laboratory processing. Fecal fat excretion was $>15 \%$ (pancreatic insufficient) for six infants, between $12 \%$ and $15 \%$ for two infants, and $5 \%-6 \%$ for three infants. Three infants who were failing to thrive at the time of diagnosis were started on enzymes (Pancrease MT 4, McNeil Pharmaceutical, Spring House, PA, U.S.A.; one-half capsule per feed) before the hospitalization for the metabolic studies; two were breast-fed and one received a cow milk-based formula. Fecal fat excretion data while on enzymes were available for two of these infants (one each on human milk and formula), and was $>15 \%$ for both.

During the metabolic studies, the formula-fed infants continued on their preadmission formulas, which included cow milk-based formulas (three low iron, two iron fortified), and semi-elemental casein hydrolysate formulas (two with high medium-chain triglycerides, one with long-chain fatty acids). Because there were no apparent trends according to type of formula, particularly with the small number of subjects for each type, all formula-fed infants were considered as one group.

The results for zinc intake, fractional absorption, and total absorbed zinc for all subjects are shown in Table 2. Mean dietary zinc intake was significantly higher for the formula-fed infants, and despite significantly lower fractional absorption, the total absorbed zinc was also significantly higher for the formula-fed group. The fractional absorption for the two breast-fed infants who were on enzymes during the study were 0.25 and 0.33 , whereas that of the formula-fed infant on enzymes was 0.10 .

Measurement of fecal excretion of endogenous zinc was possible for 11 infants, 4 breast-fed and 7 formula-fed. The complete zinc data for these 11 infants are shown in Figure 1. The means for dietary zinc intake, fractional absorption, and total absorbed zinc are similar to those of the entire group (Table 2). Mean endogenous fecal zinc was significantly greater for the formula-fed group and despite the higher amount of absorbed zinc, fecal losses were 6 times that of the breast-fed group. There was large intersubject variability in net absorption, however, and the means were not significantly different between feeding groups. The combined mean net absorption for these 11 infants was $-0.19 \pm 0.16 \mathrm{mg} / \mathrm{d}$. There was no correlation between endogenous fecal zinc and absorbed zinc $(r=0.11, p=0.75)$.

The relationship of fat malabsorption to zinc homeostasis was also examined. There was a trend for fractional absorption

Table 1. Description of subjects at start of metabolic study

\begin{tabular}{llll}
\hline & \multicolumn{1}{c}{$\begin{array}{c}\text { All subjects } \\
(15)^{*}\end{array}$} & \multicolumn{1}{c}{$\begin{array}{c}\text { Breast-fed } \\
(7)\end{array}$} & $\begin{array}{c}\text { Formula-fed } \\
(8)\end{array}$ \\
\hline Age $(\mathrm{mo})$ & $1.8 \pm 0.7 \dagger$ & $1.9 \pm 0.9$ & $1.7 \pm 0.5$ \\
Weight $(\mathrm{kg})$ & $4.2 \pm 0.8$ & $4.2 \pm 0.8$ & $4.2 \pm 0.8$ \\
Plasma zinc & & & \\
$\quad(\mu \mathrm{mol} / \mathrm{L})$ & $12.2 \pm 1.9(10)$ & $11.9 \pm 2.0(5)$ & $12.5 \pm 1.8(5)$ \\
$\quad \mu \mathrm{g} / \mathrm{dL}$ & $79.5 \pm 12.0$ & $77.6 \pm 13.2$ & $81.4 \pm 12.0$ \\
$\%$ Fecal fat excretion & $19.1 \pm 11.9(11)$ & $11.7 \pm 10.3(5)$ & $25.3 \pm 9.9(6)$ \\
\hline
\end{tabular}

* Numbers in parentheses indicate number of subjects.

$\dagger$ Data presented as mean \pm SD. 
Table 2. Summary of intake and absorption data according to feeding group

\begin{tabular}{lccc}
\hline & $\begin{array}{c}\text { All subjects } \\
(15)^{*}\end{array}$ & $\begin{array}{c}\text { Breast-fed } \\
(7)\end{array}$ & $\begin{array}{c}\text { Formula-fed } \\
(8)\end{array}$ \\
\hline Dietary zinc intake (mg/d) & $3.8 \pm 3.23 \ddagger$ & $0.95 \pm 0.42$ & $6.35 \pm 2.18$ \\
Fractional absorption & $0.26 \pm 0.20$ & $0.40 \pm 0.21$ & $0.13 \pm 0.06$ \\
Total absorbed zinc (mg/d) & $0.58 \pm 0.35$ & $0.35 \pm 0.26$ & $0.78 \pm 0.30$ \\
\hline
\end{tabular}

* Numbers in parentheses indicate number of subjects.

$\dagger$ Comparison of means according to feeding group.

$\ddagger$ Data presented as mean \pm SD.

to be negatively correlated with percent fecal fat excretion for five breast-fed infants, three of whom were pancreatic sufficient $(r=-0.90, p=0.08)$. For the formula-fed infants, four of whom were clearly pancreatic insufficient and two of whom were borderline, there was no significant correlation. Fecal fat excretion data and endogenous fecal zinc were both available for nine infants, three breast-fed (two pancreatic sufficient) and the six formula-fed infants. A significant positive correlation was found between endogenous fecal zinc and absolute $(\mathrm{g} / \mathrm{d})$ fat excretion : $r=0.89, n=9, p=0.001$ (Fig. 2).

\section{DISCUSSION}

Infants with cystic fibrosis identified by newborn screening have been found to have evidence of poor weight gain and hypoalbuminemia (15), as well as micronutrient deficiencies, including fat-soluble vitamins (16). Most recently, we have reported that zinc status is also commonly suboptimal at the time of diagnosis, and improves with the initiation of pancreatic enzyme therapy (4). The results of this study provide insights into the processes potentially responsible for development of suboptimal zinc status.

Maintenance of zinc homeostasis is critically dependent on normal function of the gastrointestinal tract through both the processes of absorption of exogenous zinc and of secretion and excretion of endogenous zinc. Fractional absorption is known to be responsive to a number of factors, including physiologic demand, absolute amount of zinc in a meal, and presence of dietary enhancers (e.g. human milk, animal proteins) or inhibitors (e.g. phytate) of absorption $(14,17)$. Although it has been suggested that the absorption process provides a "large capacity" adaptation to fluctuations in zinc intake, modulation of endogenous zinc secretion and excretion by the intestine may provide critical "fine tuning" to maintain homeostasis (14). Data are presently limited but suggest that substantial quantities of endogenous zinc are secreted with each meal (18). Maintenance of zinc balance is likely to be dependent on efficient reabsorption of much of the endogenously secreted zinc. Unlike traditional balance studies, which yield calculation of net absorption alone, the stable isotope techniques applied in the present study allow separate determinations of both of the critical processes of fractional absorption and intestinal excretion of endogenous zinc (14).

The mean fractional absorption of dietary zinc in these infants was substantially lower than figures reported for normal breast-fed and formula-fed infants $(10,19,20)$ of similar age. For normal exclusively breast-fed infants ranging in age from 2-4 mo, fractional absorption averaged $0.54 \pm 0.08$ (10). Although some of the breast-fed infants in the present study achieved similar fractional absorption, there was considerably more variability. As reflected in the negative correlation between fractional absorption and percent fecal fat excretion, those who were pancreatic sufficient tended to have normal fractional absorption. For the formula-fed infants, the difference was more marked. The mean fractional absorption was approximately half that for normal infants fed a cow milkbased, iron-fortified formula $(0.22 \pm 0.04)(20)$. We have observed significant improvement in fractional zinc absorption with pancreatic enzyme replacement in older children (21). Such an effect was not evident in these infants for either feeding type, but the apparent lack of benefit may be related to the small number of infants on enzymes and to the finding that
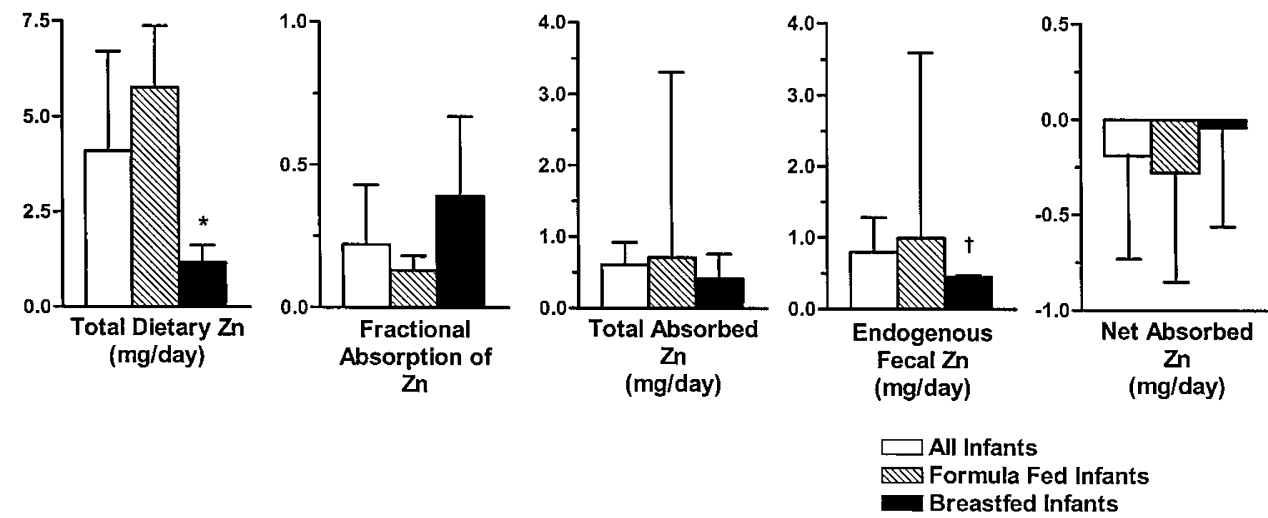

Figure 1. Mean $( \pm \mathrm{SD})$ zinc intake, fractional absorption, endogenous fecal zinc, and net absorbed zinc for infants with cystic fibrosis, according to feeding group. Significant differences between feeding groups: ${ }^{*} p<0.001 ; \dagger p<0.05$. 


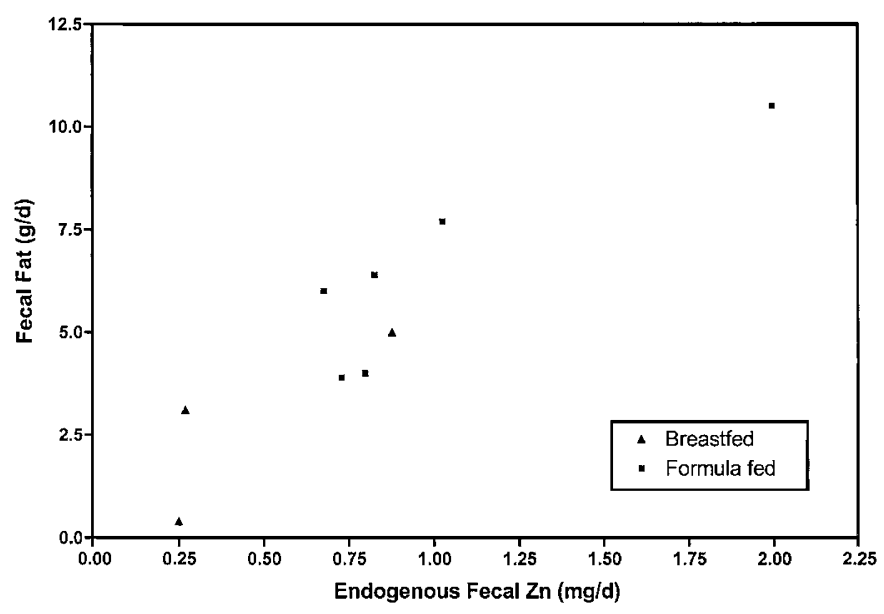

Figure 2. Spearman correlation between endogenous fecal zinc and fecal fat excretion in infants with cystic fibrosis $(r=0.89, n=9, p=0.001)$.

the enzyme replacement had not normalized fat absorption at the time of the study.

Although dietary zinc intake was very similar to that for normal infants, the relatively low fractional absorption resulted in total absorbed zinc that was lower than normal and would have been unlikely to meet requirements for growth long term. In the face of such relatively modest amounts of absorbed zinc, efficient intestinal conservation of endogenous zinc would be necessary to compensate adequately to meet the infants' nutritional needs. Rather than achieving efficient intestinal conservation, however, the absolute amounts of endogenous zinc excreted were approximately $50 \%$ higher than those observed for normal infants for both groups $(10,20)$. Furthermore, in contrast to normal infants and adults, in whom we have found significant positive correlation between total absorbed zinc and endogenous fecal zinc $(10,14,22)$, these infants showed no ability to minimize the excretion of endogenous zinc as total absorbed zinc was reduced.

The source of endogenous zinc is thought to normally be at least in part from pancreatic secretions, inasmuch as several pancreatic enzymes are zinc dependent (23). Other potential sources are biliary secretions, gastroduodenal secretions, or paracellular transport through the small intestinal mucosa. In states of low zinc intake, losses through this route are normally reduced $(10,14,19,22)$. Although it is theoretically possible that endogenous losses may be increased as a result of tissue breakdown in states of severe zinc deficiency, this has not been observed in experimentally induced moderate-to-severe zinc depletion in adults $(24,25)$. Rather, there is prompt and sustained reduction in endogenous zinc excretion. Moreover, the subjects in the present study did not have evidence of severe zinc deficiency because they were generally gaining weight during the hospitalization, had mean plasma zinc concentrations in the normal range, and none had the characteristic rash associated with severe zinc deficiency. Adult patients with chronic pancreatitis and associated steatorrhea and diabetes have been reported to have a diminished volume of pancreatic secretions, which also have lower bicarbonate and zinc content compared with controls (26). Thus, in these infants with cystic fibrosis, the majority of whom were pancreatic insufficient, excessive secretion of zinc from the pancreas seems unlikely.

We hypothesize, therefore, that interference with reabsorption, not excessive secretion, was the major factor in the high fecal losses of endogenous zinc. The strong correlation with the amount of malabsorbed fat supports this. The presence of intralumenal fatty acids has been demonstrated to result in formation of insoluble calcium soaps in animal models (27), and is generally presumed to occur in humans (28). Comparable data on the effects of unabsorbed fat, specifically undigested fat, and zinc, and the effects on zinc homeostasis in conditions with fat malabsorption are extremely limited, particularly in infants. Increased endogenous losses have been suggested to occur in adults with celiac disease (29). Although these infants were young enough to have had some degree of physiologic steatorrhea, in metabolic studies in normal breastfed infants at a similar age, we have reported lower endogenous zinc losses and positive net absorption (10).

The negative mean net absorption for both feeding types must be considered abnormal. Estimates of the requirement for net absorption of zinc to support normal growth at this age has been estimated at approximately $0.7 \mathrm{mg} / \mathrm{d}(30)$. Healthy exclusively breast-fed 2 -mo-old infants studied with similar stable isotope methods have been found to have a net zinc absorption of $0.3 \mathrm{mg} / \mathrm{d}(10)$, which supports a possible role for hepatic metallothionein as a source of zinc in the early months of postnatal life $(31,32)$. Availability of such a "store" of zinc may also explain why reports of severe zinc deficiency, with acrodermatitis enteropathica-like rash, have generally been in infants with cystic fibrosis who were older than those in this study (1-3).

The lack of sensitive biomarkers continues to complicate the assessment of zinc status and may account for the somewhat conflicting findings regarding zinc status in infants and children with cystic fibrosis $(33,34)$. The detailed metabolic data available from the present study employing stable isotope methodology provide convincing evidence of impaired zinc homeostasis in this population. The findings suggest an explanation for the observations of suboptimal zinc status in some infants at this age diagnosed by newborn screening (4), and for the clinical observations of severe zinc deficiency in some older infants before diagnosis (1-3).

The results of these studies also provide an example of apparent interference with normal conservation of endogenous zinc by the gastrointestinal tract, and an inability to compensate with increased fractional absorption. Whether these findings are unique to the pancreatic and intestinal pathologies associated with cystic fibrosis will require research under different conditions. It is plausible that unabsorbed fat represents an intralumenal factor that specifically interferes with reabsorption of endogenous zinc, as has been proposed for the mechanism through which phytate impairs zinc homeostasis (35).

Given the critical importance of normal zinc nutriture to growth and development, and immune function (36-38), these findings emphasize the importance of considering zinc deficiency in young infants with cystic fibrosis, especially in those with ongoing significant fat malabsorption and poor growth. 
Although the limitations of plasma zinc concentration as an index of zinc status are well recognized, this remains the best biomarker of zinc status available at this time (39). In a meta-analysis of zinc supplementation trials, a mean plasma zinc concentration below $80 \mu \mathrm{g} / \mathrm{dL}(12.2 \mu \mathrm{mol} / \mathrm{L})$ was a predictor of a moderately large growth response to supplementation (36). In infants or children with cystic fibrosis who have poor growth, a plasma zinc concentration should be evaluated. Furthermore, the gold standard for assessment of zinc status remains the response to a trial of zinc supplementation $(\sim 1 \mathrm{mg}$ elemental zinc $/ \mathrm{kg} / \mathrm{d})$. This is a safe and relatively easy strategy, which should also be considered in clinical circumstances when zinc deficiency is plausible.

\section{REFERENCES}

1. Hansen RC, Lemen R, Revsin B 1983 Cystic fibrosis manifesting with acrodermatitis enteropathica-like eruption: association with essential fatty acid and zinc deficiencies. Arch Dermatol 119:51-55

2. Schmidt CP, Tunnessen W 1991 Cystic fibrosis presenting with periorificial dermatitis. J Am Acad Dermatol 25:896-897

3. Ghali FE, Stenberg JB, Tunnessen WW 1996 Picture of the month. Acrodermatitis enteropathica-like rash in cystic fibrosis. Arch Pediatr Adolesc Med 150:99-100

4. Krebs NF, Sontag M, Accurso F, Hambidge KM 1998 Plasma zinc concentrations in young infants with cystic fibrosis. J Pediatr 133:761-764

5. Hammond KB, Abman SH, Sokol RJ, Accurso FJ 1991 Efficacy of statewide neonatal screening for cystic fibrosis by assay for persistent elevation of trypsinogen concentrations. N Engl J Med 325:769-774

6. Krebs NF, Reidinger C, Robertson AD, Hambidge KM 1994 Growth and intakes of energy and zinc in infants fed human milk. J Pediatr 124:32-39

7. Krebs NF, Hambidge KM, Jacobs MA, Mylet S 1985. Zinc in human milk: diurnal and within feed patterns. J Pediatr Gastr Nutr 4:227-229

8. World Health Organization 1985 The Quantity and Quality of Breast Milk, Report on the WHO Collaborative Study on Breastfeeding. World Health Organization, Geneva, Switzerland

9. Krebs NF, Hambidge KM, Jacobs MA, Oliva-Rasbach J 1985 The effects of a dietary zinc supplement during lactation on longitudinal changes in maternal zinc status and milk zinc concentrations. Am J Clin Nutr 41:560-570

10. Krebs NF, Reidinger CJ, Miller LV, Hambidge KM 1996 Zinc homeostasis in breast-fed infants. Pediatr Res 39:661-665

11. Jeejeeboy KN, Ahmad S, Kozak C 1970 Determination of fecal fats containing both medium and long chain triglycerides and fatty acids. Clin Biochem 3:157-163

12. Peirce P, Hambidge KM, Goss C, Miller L, Fennessey P 1987 The use of fast atom bombardment mass spectrometry for the analysis of zinc stable isotopes in biological samples. Anal Chem 59:2034-2037

13. Friel J, Naake V, Miller L, Fennessey P, Hambidge KM 1992 The analysis of stable isotopes in urine to determine the fractional absorption of zinc. Am J Clin Nutr 55:473-477

14. Krebs NF, Miller LV, Naake VL, Lei S, Westcott JE, Fennessey PV, Hambidge KM 1995 The use of stable isotope techniques to assess zinc metabolism. J Nutr Biochem 6:292-307

15. Bronstein MN, Sokol RJ, Abman SH, Chatfield BA, Hammond KB, Hambidge KM, Stall CD, Accurso FJ 1992 Pancreatic insufficiency, growth, and nutrition in infants identified by newborn screening as having cystic fibrosis. J Pediatr 120:533-540
16. Sokol RJ, Reardon MC, Accurso FJ, Stall C, Narkewicz M, Abman SH, Hammond KB 1989 Fat soluble-vitamin status during the first year of life by screening of newborns. Am J Clin Nutr 50:1064-1071

17. Lonnerdal B 1989 Intestinal absorption of zinc. In: Mills CF (ed) Zinc in Human Biology. Springer-Verlag, London, pp 79-93

18. Matseshe JW, Phillips SF, Malagelada JR, McCall JT 1980 Recovery of dietary iron and zinc from the proximal intestine of healthy men: studies of different meals and supplements. Am J Clin Nutr 33:1946-1953

19. Ziegler EE, Serfass RE, Nelson SE, Figueroa-Colon R, Edwards BB, Houk RS, Thompson JJ 1989 Effect of low zinc intake on absorption and excretion of zinc by infants studied with ${ }^{70} \mathrm{Zn}$ as extrinsic tag. J Nutr 119:1647-1653

20. Krebs NF, Reidinger CJ, Miller LV, Borschel M 2000 Zinc homeostasis in normal infants fed a casein hydrolysate formula. J Pediatr Gastro Nutr 30:29-33

21. Easley D, Krebs NF, Jefferson M, Miller LV, Erskine J, Accurso FJ, Hambidge KM 1998 Effect of pancreatic enzymes on zinc absorption in cystic fibrosis. J Pediatr Gastro Nutr 26:136-139

22. Lei S, Xiang M, Miller LV, Krebs NF, Lei T, Hambidge, KM 1996 Zinc absorption and intestinal losses of endogenous zinc in young Chinese women with a marginal zinc intake. Am J Clin Nutr 63:348-353

23. Hambidge KM, Casey CE, Krebs NF 1986 Zinc. In: Mertz W (ed) Trace Elements in Human and Animal Nutrition, 5th Ed, Vol 2. Academic Press, Orlando, FL, pp 1-137

24. Lee DY, Prasad AS, Hydrick-Adair C, Brewer G, Johnson PE 1993 Homeostasis of zinc in marginal human zinc deficiency: role of absorption and endogenous excretion of zinc. J Lab Clin Med 122:549-556

25. Taylor CM, Bacon JR, Aggett PJ, Bremner I 1991 Homeostatic regulation of zinc absorption and endogenous losses in zinc-deprived men. Am J Clin Nutr 53:755-763

26. Sullivan JF, O'Grady J, Lankford HG 1965 The zinc content of pancreatic secretion. Gastroenterology 48:438-442

27. Gacs G, Barltrop D 1977 Significance of Ca-soap formation for calcium absorption in the rat. Gut 18:64-68

28. Allen LH, Wood RJ 1994 Calcium and phosphorus. In: Shils ME, Olson JA, Shike M (eds) Modern Nutrition in Health and Disease. Lea \& Feiberger, Philadelphia, pp $151-152$

29. Crofton RW, Aggett PJ, Gvozdanovic S, Gvozdanovic D, Mowat NAG, Brunt PW 1990 Zinc metabolism in celiac disease. Am J Clin Nutr 52:379-382

30. Krebs NF, Hambidge KM 1986 Zinc requirements and zinc intakes of breast fed infants. Am J Clin Nutr 43:288-292

31. Zlotkin SH, Cherian MG 1988 Hepatic metallothionein as a source of zinc and cysteine during the first year of life. Pediatr Res 24:326-329

32. Coni P, Ravarino A, Farci AMG, Callea F, VanEyken P, Sciot R, Ambu R, Marras A, Costa V, Faa G, Desmet VJ 1996 Zinc content and distribution in the newborn liver. J Pediatr Gastro Nutr 23:125-129

33. Caillie-Bertrand MV, DeBieville F, Neijens H, Kerrebijn K, Fernandes J, Degenhart H 1982 Trace metals in cystic fibrosis. Acta Paediatr Scand 71:203-207

34. Kelleher J, Goode HF, Field HP, Walker BE, Miller MG, Littlewood JM 1986 Essential element nutritional status in cystic fibrosis. Hum Nutr Appl Nutr 40A:79-84

35. Oberleas D 1996 Mechanism of zinc homeostasis. J Inorg Biochem 62:231-241

36. Brown KH, Peerson JM, Allen LH 1998 Effect of zinc supplementation on children's growth: a meta-analysis of intervention trials. Bibl Nutr Dieta 54:76-83

37. Shankar AH, Prasad AS 1998 Zinc and immune function: the biological basis of altered resistance to infection. Am J Clin Nutr 68(suppl):447S-463S

38. Mocchegiani E, Provincialli M, DiStefano G, Nobilini A, Caramia G, Santarelli L, Tibaldi A, Fabris N 1995 Role of the low zinc bioavailability on cellular immune effectiveness in cystic fibrosis. Clin Immunol Immunopathol 75:214-224

39. Hambidge M, Krebs N 1995 Assessment of zinc status in man. Indian J Pediatr 62:169-180 